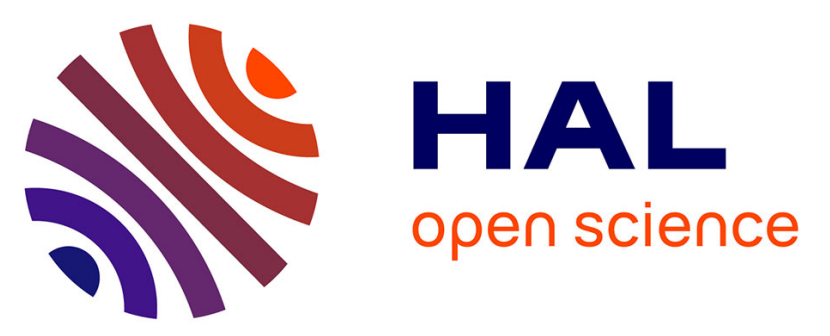

\title{
Pilot Flying and Pilot Monitoring's Aircraft State Awareness During Go-Around Execution in Aviation: A Behavioral and Eye Tracking Study
}

Frédéric Dehais, Julia Behrend, Vsevolod Peysakhovich, Mickaël Causse, Christopher D. Wickens

\section{To cite this version:}

Frédéric Dehais, Julia Behrend, Vsevolod Peysakhovich, Mickaël Causse, Christopher D. Wickens. Pilot Flying and Pilot Monitoring's Aircraft State Awareness During Go-Around Execution in Aviation: A Behavioral and Eye Tracking Study. The International Journal of Aerospace Psychology, 2017, vol. 27 ( $\left.\mathrm{n}^{\circ} 1-2\right)$, pp. 15-28. 10.1080/10508414.2017.1366269 . hal-01655050

\author{
HAL Id: hal-01655050 \\ https://hal.science/hal-01655050
}

Submitted on 4 Dec 2017

HAL is a multi-disciplinary open access archive for the deposit and dissemination of scientific research documents, whether they are published or not. The documents may come from teaching and research institutions in France or abroad, or from public or private research centers.
L'archive ouverte pluridisciplinaire HAL, est destinée au dépôt et à la diffusion de documents scientifiques de niveau recherche, publiés ou non, émanant des établissements d'enseignement et de recherche français ou étrangers, des laboratoires publics ou privés. 


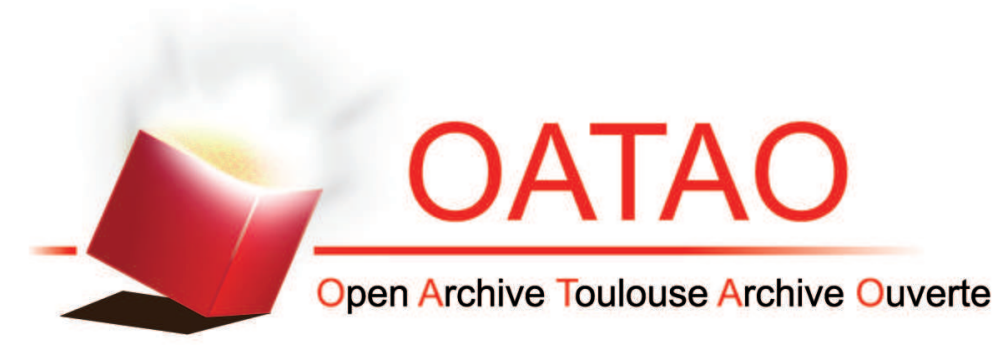

\section{Open Archive Toulouse Archive Ouverte (OATAO)}

OATAO is an open access repository that collects the work of some Toulouse researchers and makes it freely available over the web where possible.

This is an author's version published in: https://oatao.univ-toulouse.fr/18570

Official URL : http://dx.doi.org/10.1785/0220170094

\section{To cite this version :}

Dehais, Frédéric and Behrend, Julia and Peysakhovich, Vsevolod and Causse, Mickaël and Wickens, Christopher D. Pilot Flying and Pilot Monitoring's Aircraft State Awareness During Go-Around Execution in Aviation: A Behavioral and Eye Tracking Study. (2017) The International Journal of Aerospace Psychology, vol.27 ( $\left.n^{\circ} 1-2\right)$. pp. 15-28. ISSN 2472-1840

Any correspondence concerning this service should be sent to the repository administrator: tech-oatao@listes-diff.inp-toulouse.fr 


\title{
Pilot Flying and Pilot Monitoring's Aircraft State Awareness During Go-Around Execution in Aviation: A Behavioral and Eye Tracking Study
}

\author{
Frédéric Dehais $\mathbb{1}^{\mathrm{a}}$, Julia Behrend ${ }^{\mathrm{a}, \mathrm{b}}$, Vsevolod Peysakhovich ${ }^{\mathrm{a}}$, Mickaël Causse ${ }^{\mathrm{a}}$, \\ and Christopher D. Wickens ${ }^{c}$ \\ anstitut Supérieur de l'Aéronautique et de I'Espace (ISAE-SUPAERO), Université Fédérale de Toulouse, Toulouse, \\ France; 'baboratoire de Neurosciences Cognitives, Département d'Etudes Cognitives, Ecole Normale Supérieure, PSL \\ Research University, Paris, France; 'Colorado State University and The University of Illinois at Urbana-Champaign, \\ Emeritus
}

\begin{abstract}
Objective: Examination of the performance and visual scanning of aircrews during final approach and an unexpected go-around maneuver.

Background: Accident and incident analyses have revealed that goaround procedures are often imperfectly performed because of their complexity, their high time stress, and their rarity of occurrence that avails little time for practice. We wished to examine this experimentally and establish the frequency and nature of errors in both flight-performance and visual scanning.

Method: We collected flight-performance (e.g., errors in procedures, excessive flight deviations) and eye-tracking data of 12 flight crews who performed final approach and go-around flight phases in realistic full-flight transport-category simulators.

Results: The pilot performance results showed that two thirds of the crews committed errors including critical trajectory deviations during go-arounds, a precursor of accidents. Eye-tracking analyses revealed that the cross-checking process was not always efficient in detecting flight-path deviations when they occurred. Ocular data also highlighted different visual strategies between the 2 crew members during the 2 flight phases.

Conclusion: This study reveals that the go-around is a challenging maneuver. It demonstrates the advantages of eye tracking and suggests that it is a valuable tool for the explicit training of attention allocation during go-arounds to enhance flight safety.
\end{abstract}

In commercial aviation, the final-approach phase is one of the most dynamic flight segments, for which safety margins are minimum and time pressure is maximum. Numerous undesired external events or crew failure to stabilize the flight path or to configure the aircraft for landing could lead to the execution of a go-around. Flight crews, composed of a pilot flying (PF) and a pilot monitoring (PM), are trained to land the aircraft or to perform a go-around according to standard operating procedures (U.S. Department of Transportation, 2015). During go-around, the PF's task is to manage the missed-approach flight path while giving instructions to the PM (e.g., retracting the flaps and the landing gear). The PM carefully monitors the flight path and the status of the aircraft and executes the PF's instructions.

CONTACT Frédéric Dehais Frederic.dehais@isae.fr 0 Institut Supérieur de l'Aéronautique et de l'Espace (ISAE-SUPAERO), Université Fédérale de Toulouse, 10 avenue Edouard Belin, 31055 Toulouse Cedex 4, France. 
Despite this defined task distribution, more than 25 critical events occurred during go-around execution between 1985 and 2010. Their consequences were serious in terms of fatalities (954; BEA, 2013). The Bahrain accident in 2006 (BEA, 2013) is an example when the captain applied incorrect pitch control during go-around, was distracted by an auditory warning, and continued until the aircraft impacted the sea. The investigation commission highlighted that the copilot (PM) did not perform his monitoring duties correctly (BEA, 2000). As emphasized by the National Transportation Safety Board (NTSB) and the International Civil Aviation Organization (ICAO), pilots' poor flight-path monitoring was a contributive factor in most of major civilian accidents (NTSB, 2013), such as Colgan Air Flight 3407 (Spangler \& Park, 2010), Asiana Air Flight 214 (NTSB, 2015), Turkish Airlines Flight 1951 (Dutch Safety Board, 2010), or more recently UPS Airlines Flight 1354 (NTSB, 2013) to name a few (UK Civilian Aviation Authority, 2013). Consistently, the Active Pilot Monitoring Group identified several contributing factors to these events, among which was a "corporate climate that does not emphasize on monitoring" (FSF, 2014).

To determine the nature and the frequency of errors and the pilots' related visual scanning during go-around, the BEA (the French Accident Investigation Bureau) initiated the Aeroplane State Awareness during Go-Around (ASAGA) study (BEA, 2013). This study consisted of two main components: a survey and an observational eye-tracking study in full-flight simulators, the core of this article.

The results of the first component, the survey, reported that a go-around was a rather infrequent event, although it is considered as a standard maneuver regularly practiced in airlines' flight simulators. Indeed, the survey showed that a medium-haul flight crew performed on average one go-around per year during commercial flight, whereas a long-haul flight crew experienced one goaround every 5 to 10 years (BEA, 2013). This rather low-frequency experience in realistic settings may leave the pilots ill-equipped to switch from an expected goal (landing) to a highly-dynamic procedure that may challenge humans' mental capacities. Pilots' response to low-probability events represents a critical component for aviation safety (Pinet \& Sheridan, 2016; Wickens, Hooey, Gore, Sebok, \& Koenicke, 2009). The results of the survey (BEA, 2013) also stressed that pilots identified three critical elements that made the execution of the go-around complex. First, a dense communication with air traffic control (ATC) was cited as a possible overloading factor that disturbed the pilots' conscious plan of actions, particularly when clearance differed from the expected procedurespecified go-around trajectory. Second, complex automation management, excessive thrust power, and rapid, precise actions were considered factors that induced time pressure. Third, pilots were unanimous in reporting confusion, attentional impairment, and poor crew-resource management leading to poor task sharing during the go-around maneuver. This situation can reduce flying performance, as previous research has shown the influence of stress on cognitive performance in aviation (Dehais, Tessier, Christophe, \& Reuzeau, 2010; Pizziol, Tessier, \& Dehais, 2014; Starcke \& Brand, 2012; Stokes \& Kite, 1994). In particular, time pressure might direct the flight crew to use fewer channels of information (Stokes, Kemper, \& Marsh, 1992; Tessier \& Dehais, 2012).

The objective of the second component of the ASAGA study, namely the observational simulator study, was to assess pilots' monitoring abilities during final approach and go-around. An interesting prospect to understand a pilot's visual scan is to consider eye tracking. Several studies confirmed that measuring dwell times in the cockpit offered an insight into pilots' visual behavior (Dehais, Causse, \& Pastor, 2008; Kasarskis, Stehwien, Hickox, Aretz, \& Wickens, 2001; Mumaw, Sarter, \& Wickens, 2001; Reynal, Rister, Scannella, Wickens, \& Dehais, 2017; Sarter, Mumaw, \& Wickens, 2007; Wickens et al., 2008). Additionally, the computation of the number of fixations and saccades can reveal basic visual strategies, and it can be an indicator of information processing (Dehais, Peysakhovich, Scannella, Fongue, \& Gateau, 2015; Regis, Dehais, Tessier, \& Gagnon, 2012).

To link flight performance and eye movements, we designed a scenario in which crews performed a final approach and a go-around procedure in realistic full-flight (per the National Aviation Authority [NAA] definition; meaning a high technical level of flight simulation) transport-category aircraft simulators. One novelty of this study was to collect both the PF's and PM's eye movements, a goal that has rarely been achieved before (Reynal, Colineaux, Vernay, \& Dehais, 2016). The scenario included 
the main critical features identified during the survey: a nonanticipated go-around (i.e., ATC requested the go-around at the last moment) and a nonstandard go-around trajectory. Our goal was to determine the percentage of pilots who would make errors in attempting the go-around and the nature and frequency of these errors. We collected eye-tracking data to assess the effect of the go-around maneuver on the PF's and PM's dwell time. Additionally, our objective was to relate visual behavior to the errors of commission and omission in the go-around and to determine how visual behavior affected performance and determine how instrument-scanning behavior differed from expectations regarding the pilot role (PF vs. PM).

\section{Material and Method}

\section{Participants}

Twenty-four French professional airline pilots (PFs $M$ age $=49.8$ years, $S D=4.9$, mean flight experience $=14,540 \mathrm{hr}, S D=2573.51$; PM's $M$ age $=41$ years, $S D=4.7$, mean flight experience $=8743.5 \mathrm{hr}, \mathrm{SD}=2733.3 ; 2$ females: $1 \mathrm{PF}$ and $1 \mathrm{PM}$ ) voluntarily participated in this observational study. Each of the 12 flight crews was composed of a captain (PF) and a first officer (PM). As in real airline situations, crews were not necessarily familiar with each other and were randomly paired. All participants were informed about the study and gave written consent before participating.

\section{Protocol}

Two different twin-engine simulators were used for the experiment: seven crews flew on a Boeing 777 fullflight simulator and five crews flew on an Airbus 330 full-flight simulator. Aircraft type was not of fundamental interest in the study. The crews were instructed that the simulator sessions aimed to study the human visual system during a standard flight. Importantly, we did not inform the pilots about a forthcoming go-around. However, pilots knew the published go-around procedure for a selected runway. This is a specific element of the approach briefing. To increase pilots' workloads, (a) the flight was conducted during the night, (b) ATC requested the go-around at the last moment, and (c) ATC's instructions differed from the published missed approach procedure, as sometimes happens during go-arounds.

The general scenario was as follows: a night flight lasting about 40 min, taking off from Bordeaux and heading to Lyon. During descent, ATC asked the pilots to perform a manual Instrument Landing System (ILS) approach to Runway 35L. The runway became perfectly visible when the aircraft descended below a height of 1,000 ft. Without advance notice, at a height below $200 \mathrm{ft}$, ATC contacted the crew to indicate the presence of traffic on the runway and asked for an immediate go-around. Unlike the published go-around, which requires the crew to climb in the runway's axis on a magnetic heading of 354 to an altitude of 5,000 ft, ATC instructed the crew to turn left on a heading of $340^{\circ}$ and to climb and level off at an altitude of $2,500 \mathrm{ft}$. This ATC request induced a go-around at low altitude with a disruption caused by the new trajectory. We expected that this maneuver combining a turn and a simultaneous climb with an altitude limitation would surprise the crew and increase time pressure, making flight-path and energy management more difficult.

\section{Measurements}

Our analysis first focused on the crews' performance, such as response time and errors. Second, we performed group analyses on dwell times and basic eye movements to determine how the onset and the management of the go-around affected the PF's and PM's visual attention allocation. Third, we related crews' errors to eye movements through quantitative and qualitative analyses to determine how PF and PM visual scan affected flight performance. 


\section{Pilot Flight-Performance Analysis}

A high-definition (HD) video camera was set up in the cockpit to allow us to monitor the flight parameters displayed on the flight deck, crews' actions, and their verbal communications. We analyzed crews' compliance with standard operating procedures; that is, pilots' actions and the correct order of these actions during go-around. The go-around is announced by the PF, who applies full power and adopts a positive climb, rotating to the go-around pitch target. The PM retracts the flaps and monitors the vertical-speed indicator. Once the positive climb is confirmed by the PM, the PF orders "gear up," and the action is executed by the PM. During the execution of the maneuver, the crews must carefully monitor the flight path and the speed. In summary, we used the HD camera to analyze the crews' reaction time to execute the maneuver (i.e., from the moment they applied full-throttle to the moment they reached the requested altitude $-2,500 \mathrm{ft}$-with the correct heading, $340^{\circ}$ ). The crews' ability to perform the expected actions and to read back the clearance instruction was also assessed with the video material. The BEA experts identified flight path deviation from the go-around requested trajectory $\left(340^{\circ}, 2,500 \mathrm{ft}\right)$ : Any lateral deviations exceeding $\pm 20^{\circ}$ and vertical deviations greater than $200 \mathrm{ft}$ were considered flight-path excursions. After the experiment, a debriefing was conducted to collect the PM's and PF's subjective data.

\section{Eye Tracking}

The participants' eye movements were recorded using two $50 \mathrm{~Hz}$ head-mounted Pertech ${ }^{\varpi}$ eye-trackers. The participants' fixations were mapped on an image of reference, chosen for each participant so that it contained 14 areas of interest (AOIs; see Figure 1). However, to reduce the number of comparisons, the data analysis was focused primarily on the six AOIs that received the majority of visual scans.

For each participant, we analyzed two flight phases: final approach starting from $2,500 \mathrm{ft}$, and goaround (until the stabilization of the aircraft at 2,500 ft). For the purposes of analysis, the data were categorized by aircraft type (2: Boeing, Airbus), pilot role (2: PF, PM), flight phase (2: final approach, go-around), and the six most viewed AOIs. First, mean dwell time on each of the six AOIs was calculated. Second, to perform complementary basic analyses of eye movements, we determined the occurrence of fixations and saccades through the whole eye-tracking recording. Eye movements under $30 \%$ and not exceeding $1^{\circ}$ in dispersion were considered as fixations (as in Dehais et al., 2015). The computation of an eye metric based on the fixation and saccade ratio was then used to express the balance between the different visual strategies of explore (visual search) and exploit (i.e., visual processing) (Goldberg \& Kotval, 1999). Similar to Dehais et al. (2015), we first selected eye movements that resulted in a Cohen's $d$ value greater than .8 , considered a large effect size (Cohen, 1992). This led us to identify four categories of eye movements: (a) short fixations of 40 to $80 \mathrm{~ms}$, (b)
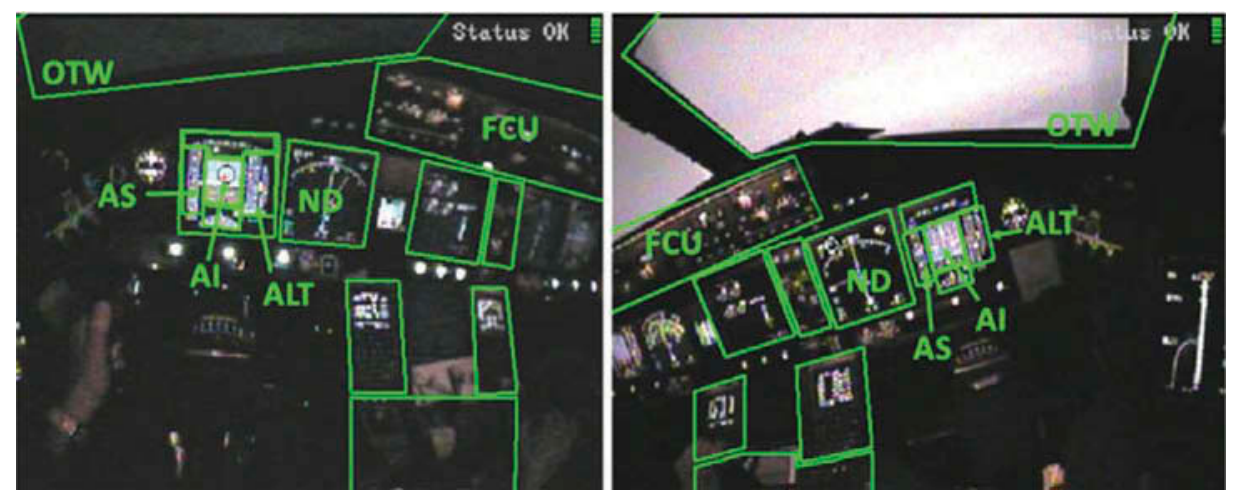

Figure 1. An example of reference images and areas of interests (AOls) for pilot flying (at left) and pilot monitoring (at right). We focused our analyses on the six AOls that received the majority of scans: airspeed (AS), attitude indicator (Al), altitude indicator (ALT), navigation display (ND), flight control panel (flight control unit for Airbus and mode control panel for Boeing), and out of the window (OTW). 
medium fixations of 180 to $220 \mathrm{~ms}$, (c) long fixations of 340 to $500 \mathrm{~ms}$, and (d) saccades of 140 to $260 \mathrm{~ms}$. We then constructed a modified ratio defined as $\mathrm{R}=$ (short fixations + saccades)/(medium fixations + long fixations). High $\mathrm{R}$ values indicate explore behavior (visual search) whereas low $\mathrm{R}$ values expressed exploit behavior (processing; Dehais et al., 2015; Goldberg \& Kotval, 1999).

\section{Results}

\section{Pilot Performance During the Execution of the Go-Around}

All of the participants correctly initiated the go-around procedure and managed to stabilize the aircraft in accordance with the ATC clearance. The mean response time to complete the go-around maneuver (i.e., heading $340^{\circ}$, altitude $\left.2,500 \mathrm{ft}\right)$ was $74.7 \mathrm{~s}(S D=14.92)$. Only 3 aircrews $(1,3,11)$ out of 12 were able to read back the complete go-around clearance on their initial response (i.e., heading 340, altitude 2,500), and 2 aircrews remembered only one piece of information (2 and 5) and thus had to ask ATC to repeat the missed instructions. The remaining 7 crews had to call back ATC to repeat the complete clearance so as to dial the settings in the flight control unit (FCU). Six crews experienced lateral $(2,8)$, vertical $(7,9$, 10 ), or both lateral and vertical (11) trajectory deviation, mostly due to poor interaction with the FCU (2, $7,9,10,11)$. Eventually, one PM (1) did not retract the landing gear. Table 1 provides detailed information about each crew's performance. No overt differences in performance (i.e., time to complete the go-around, errors) were observable between the two types of aircraft simulated.

Table 1. Crews' performance related to visual scanning during go-around maneuver.

\begin{tabular}{|c|c|c|c|c|c|}
\hline \multirow[b]{2}{*}{$\begin{array}{l}\text { Aircrew } \\
\text { No. }\end{array}$} & \multicolumn{2}{|c|}{ Performance Errors } & \multicolumn{2}{|c|}{ PF's Visual Cross-Checks } & \multirow{2}{*}{$\begin{array}{l}\text { PM's Visual Cross-Checks } \\
\text { Go-Around Flight Path }\end{array}$} \\
\hline & PM & PF & FCU Settings & $\begin{array}{l}\text { Landing } \\
\text { Gear }\end{array}$ & \\
\hline 1 & Landing gear not retracted & None & $\nabla$ & $\square$ & $\nabla$ \\
\hline 2 & $\begin{array}{l}\text { Dialed an erroneous } \\
\text { heading }\left(240^{\circ}\right) \text { although } \\
\text { he announced } 340^{\circ}\end{array}$ & $\begin{array}{l}\text { Heading deviation } \\
\left(40^{\circ}\right)\end{array}$ & $\square$ & $\nabla$ & $\begin{array}{l}\text { पChecked the FMA then shifted } \\
\text { to airspeed/flaps management }\end{array}$ \\
\hline 3 & None & None & $\nabla$ & $\square$ & $\nabla$ \\
\hline 4 & None & None & $\nabla$ & $\nabla$ & $\nabla$ \\
\hline 5 & $\begin{array}{l}\text { Heading mode not } \\
\text { correctly engaged }\end{array}$ & None & $\nabla$ & $\square$ & $\nabla$ \\
\hline 6 & None & None & $\nabla$ & $\nabla$ & $\nabla$ \\
\hline 7 & $\begin{array}{l}\text { Did not set the altitude on } \\
\text { the FCU }\end{array}$ & $\begin{array}{l}\text { Altitude exceeded } \\
(500 \mathrm{ft})\end{array}$ & $\nabla$ & $\square$ & $\begin{array}{l}\text { पChecked the flight path but } \\
\text { quick shift to airspeed/flaps } \\
\text { management when the altitude } \\
\text { was about to be exceeded }\end{array}$ \\
\hline 8 & None & $\begin{array}{l}\text { Heading deviation } \\
\left(25^{\circ}\right)\end{array}$ & $\begin{array}{l}\text { DExcessively } \\
\text { focused on the } \\
\text { vertical trajectory } \\
\text { on the flight } \\
\text { director }\end{array}$ & $\nabla$ & $\begin{array}{l}\text { 口Checked only vertical profile } \\
\text { then shifted to airspeed/flaps } \\
\text { management }\end{array}$ \\
\hline 9 & $\begin{array}{l}\text { Late setting of the altitude } \\
\text { on the FCU }\end{array}$ & $\begin{array}{l}\text { Altitude exceeded } \\
(600 \mathrm{ft}) \text { - activation } \\
\text { of altitude alert }\end{array}$ & $\square$ & $\square$ & $\begin{array}{l}\text { DExcessively focused on the FCU } \\
12 \mathrm{~s}\end{array}$ \\
\hline 10 & $\begin{array}{l}\text { Announced the vertical } \\
\text { deviation-Altitude } \\
\text { exceeded (1,400 ft) and } \\
\text { activation of altitude alert }\end{array}$ & $\begin{array}{l}\text { Very late settings on } \\
\text { the FCU } \\
\text { (target altitude had } \\
\text { already been } \\
\text { overshot) }\end{array}$ & $\nabla$ & $\square$ & $\nabla$ \\
\hline 11 & $\begin{array}{l}\text { Did not engage the } \\
\text { altitude properly }\end{array}$ & $\begin{array}{l}\text { Altitude exceeded } \\
(200 \mathrm{ft}), \text { heading } \\
\text { deviation }\left(20^{\circ}\right)\end{array}$ & $\square$ & 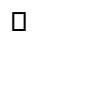 & $\begin{array}{l}\text { DExcessively focused on the FCU } \\
15 \mathrm{~s}\end{array}$ \\
\hline 12 & None & None & $\nabla$ & 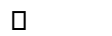 & $\nabla$ \\
\hline
\end{tabular}

Note. Checked box indicates that pilots (pilot monitoring [PM] or pilot flying [PF]) visually cross-checked each other's actions, whereas an empty box indicates they did not. Crews who experienced flight-path deviations are highlighted in gray. FCU $=$ flight control unit; FMA = Flight Mode Annunciator. 


\section{Eye Tracking Analyses at the Group Level: Assessing the Impact of the Go-Around on PF's and PM's Visual Attention Distribution}

Inferential statistical analyses were performed using R with the "Ezanova" package (see https://www.rproject.org/). Repeated-measures analysis of variance (ANOVA) was used to examine main and interaction effects of the AOIs, the pilot role (PF or PM), and the flight phase (final approach and go-around).

\section{AOI Percent Dwell Time}

Preliminary analysis of the eye-tracking data revealed that a vast majority (79\%) of the fixations were focused on the six most-viewed AOIs (i.e., mean dwell time above $5 \%$ in at least one condition). Hence, the subsequent analyses of AOI dwell times were exclusively focused on AOIs defining out-the-window (OTW), Attitude Indicator (AI), airspeed (AS), altimeter (ALT), navigation display (ND), FCU.

An initial $6 \times 2(6$ AOIs $\times 2$ types of aircraft $)$ ANOVA showed no main effect of aircraft type, $F(5,50)=2.92, p>.05, \eta^{2} \mathrm{p}=.005$; and no Aircraft Type $\times$ AOI interaction effect, $F(5,50)=0.46$, $\left.p>.05, \eta^{2} \mathrm{p}=.04\right)$. This result was expected, as the flight decks of these two airplanes are similar. All subsequent analyses were therefore collapsed over airplane type.

To check the consistency of our data, we compared them with those of Sarter et al. (2007; see Steelman, McCarley, \& Wickens, 2011) to suggest that there is generally a close correspondence between the PF's scanning behavior recorded here, and the one of the PF in the 747 simulation (Sarter et al., 2007) during the approach phase. Across five AOIs in our analyses (FCU data were removed because equivalent data were not available from Sarter et al., 2007), the correlation in mean dwell time between the two studies indicated a good agreement $(r=.88, p<.10)$.

A $6 \times 2 \times 2(6$ AOIs $\times 2$ pilots $\times 2$ flight phases $)$ ANOVA on these data yielded a significant effect of AOI, $F(5,110)=60.05, p<.0001, \eta^{2} \mathrm{p}=0.73$; and a significant AOI $\times$ Pilot interaction, $F(5$, $110)=21.21, p<.0001, \eta^{2} \mathrm{p}=0.49$.

Our particular interest was in the shift of (a) total visual attention of the crew, and (b) differential monitoring by each crew member, as the aircraft moves from a normal final approach to an offnominal go-around. The data are presented in a different panel for each AOI (see Figure 2).

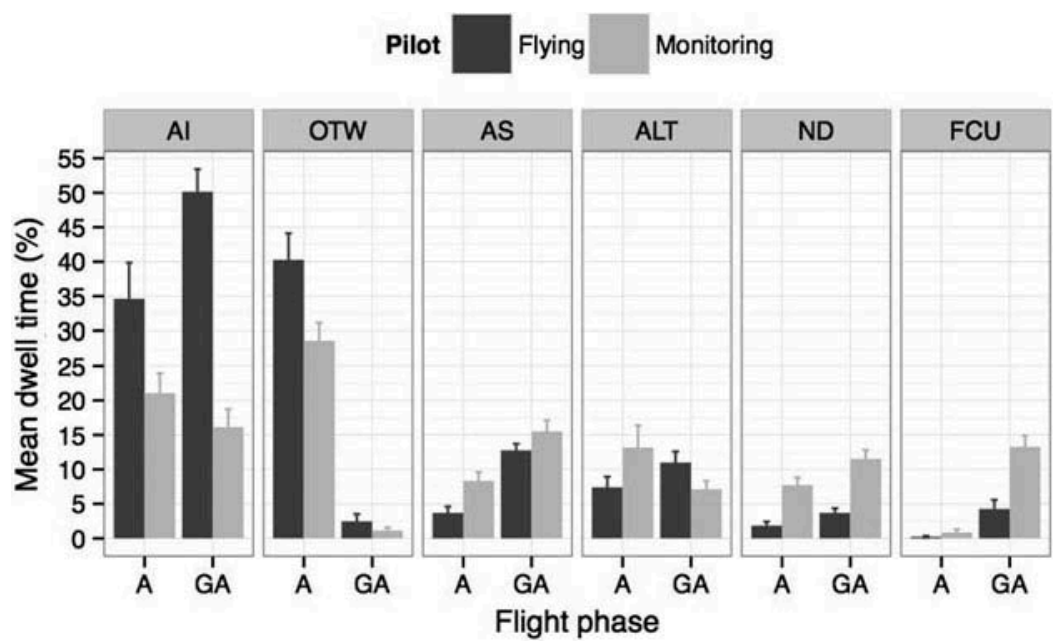

Figure 2. Distribution of pilot flying's and pilot monioring's eye gaze on the six main areas of interest during the final approach (A) and the go-around (GA). Al = attitude indicator; OTW = out the window; $A S=$ airspeed; $A L T=$ altitude indicator; $N D=$ navigation display; FCU = flight control unit. 
The different changes in scanning behaviors within Figure 2, discussed here, were statistically significant as indicated by the three-way interaction between pilot, flight phase, and AOI, $F(5,110)=8.391, p<.0001, \eta^{2} p=0.27$. These scanning behaviors within each panel are then analyzed by the $2 \times 2$ ANOVA on the four data points within each:

- Both pilots neglected the outside world (OTW) scanning (second panel) during the go-around, just as both paid more attention to monitor carefully the airspeed indicator (AS; third panel) so it does not drop below minimum (stall) or exceed maximum (velocity flaps extended limit) values, and the navigation display (ND; fifth panel). These are reflected in the main effect of flight phase within each of these three AOIs: OTW, $F(1,22)=204, p<.001$; AS, $F(1,22)=32.8$, $p<.001 ; \mathrm{ND}, F(1,22)=10.1, p<.01$.

- A differential shift is shown on the attitude indicator (AI; first panel), as revealed by a significant Pilot $\times$ Phase interaction, $F(1,22)=13.2, p<.01$, which received substantially more attention from the PF (Honest Significant Difference [HSD] $<.001$ ) during the go-around. The PF fixated more on the AI than did the PM $(p<.001)$ when performing the go-around to apply the correct reference pitch angle to avoid a stall. Another differential shift, to the FCU, was revealed in the significant Pilot Role $\times$ Flight Phase interaction, $F(1,22)=17.5, p<.001$, which also confirmed that the FCU (sixth panel) received much more attention shift from the PM than from the PF $(\mathrm{HSD}<.01$.)

\section{Eye Movements and Explore/Exploit Ratio}

Following the procedures of Dehais et al. (2015), we measured the explore/exploit ratio. We conducted a 2 (pilot role) $\times 2$ (flight phase) ANOVA to examine the interaction between the pilot role and the flight phase on the ratio. Tukey's HSD test was used for post-hoc comparisons. The data for the constructed explore/exploit ratio are shown in Figure 3, and the ANOVA revealed the main effect of the pilot role, $F(1,11)=10.09, p<.01, \eta 2=0.48$, corresponding to higher explore activity for PM. The interaction between the two factors was significant, $F(1$, $11)=18.03, p<.01, \eta 2=0.62$. As Figure 3 shows, during go-around, but not approach, the PM engaged in much more exploratory behavior than did the pilot. The mean ratio of the PF during the go-around procedure was significantly lower than the ratio for the PM during final approach $(\mathrm{HSD}<.05)$ and go-around $(\mathrm{HSD}<.01)$ phases.

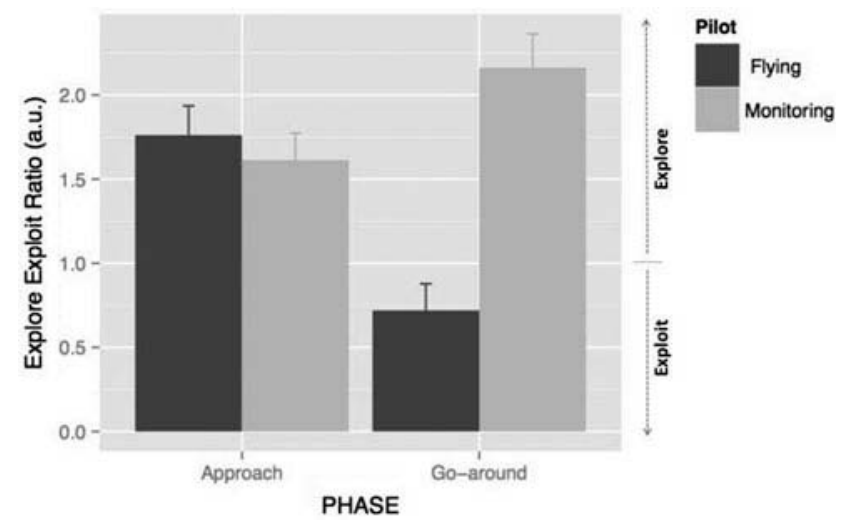

Figure 3. Mean explore/exploit ratios for pilot flying and pilot monitoring for final approach and go-around phases. Higher values indicate an increase of the explore mode, whereas lower values reflect an increase of the exploitation mode. Bars represent standard errors. 


\section{Pilot Performance and Related Eye Tracking Analyses: Assessing the Efficiency of the PF's and the PM's Visual Scan and Cross-Checking}

The previous statistical analyses highlighted the finding that both pilots exhibited different ocular behaviors during the go-around. Nevertheless, these analyses at a group level could not distinguish between crews who effectively managed the go-around and crews who did not. For convenience, we labeled them as best performing crews and poorest performing crews, respectively. To examine what features of scanning might differentiate the two cases, we selected the six best crews, who did not experience any of the BEA-scored flight path deviations (Crews 1, 3 , $4,5,6,12$ ), and the six poorest who did (Crews 2, 7, 8, 9, 10, 11). We performed a logistic regression with the six main AOIs as predictors and the group performance as binomial outcome (i.e., best vs poorer). This regression yielded only one of the AOIs, airspeed, that distinguished the two skill levels $(p=.03)$. Figure 4 depicts that this effect is particularly important for the PMs. PMs in poorer crew groups paid considerably (40\%) less attention to airspeed monitoring than the ones in the best performing crew groups.

To gain a deeper understanding at an individual level, we then conducted qualitative analyses to examine pilots' performance errors (PM errors vs. PF errors) and their ability to "visually" crosscheck critical flight parameters (see Table 1). For instance, we checked to determine if the PFs glanced at the landing-gear indicator right after the PFs' action because one PM forgot to retract it. We also verified if the PFs checked the PMs' settings by glancing at the ND or at the FCU because some PMs did not interact correctly with the autoflight panel.

Figure 5 illustrates poor monitoring skills of one pilot (PM 11; see Table 1). This PM exhibited excessive focus on entering the data into the $\operatorname{FCU}\left(2,500 \mathrm{ft}, 340^{\circ}\right)$ for $15 \mathrm{~s}$ to the detriment of the monitoring of the flight deck. Black dots indicate the current gaze position, time origin being aligned to the initiation of the go-around procedure.

Table 1 gave us some insights into the visual cross-checking behavior of both pilots. To gain a deeper understanding of the crews' overall visual attention on important flight-path parameters during go-around, we examined how much time the crew neglected critical parameters related to the energy and the trajectory of the airplane. Therefore, we measured the maximum lapse of time during which those AOIs were not glanced at by any of the crew members, PM or PF (i.e., the period of neglect or "first passage time;" Moray, 1986). Figure 6 represents the crews' median values of the longest period without a fixation on the primary flight parameters: speed, attitude indicator, altitude indicator and ND. Figure 6 shows that primary flight parameters such as the airspeed or altitude



Figure 4. Percentage of dwell time (\%) on the airspeed indicator predict crews' differential performance during the go-around (poorer vs. best performing crews). Bars represent standard error. 
were sometimes not monitored by any of the crew members during more than $12 \mathrm{~s}$ or $14 \mathrm{~s}$, respectively. However this neglect period did not differ statistically between the two performance groups.

\section{Discussion}

In this observational study, 12 crews, equipped with eye trackers, were placed in realistic flight simulators, facing a demanding go-around scenario. Our measurements allowed us to address the following questions.

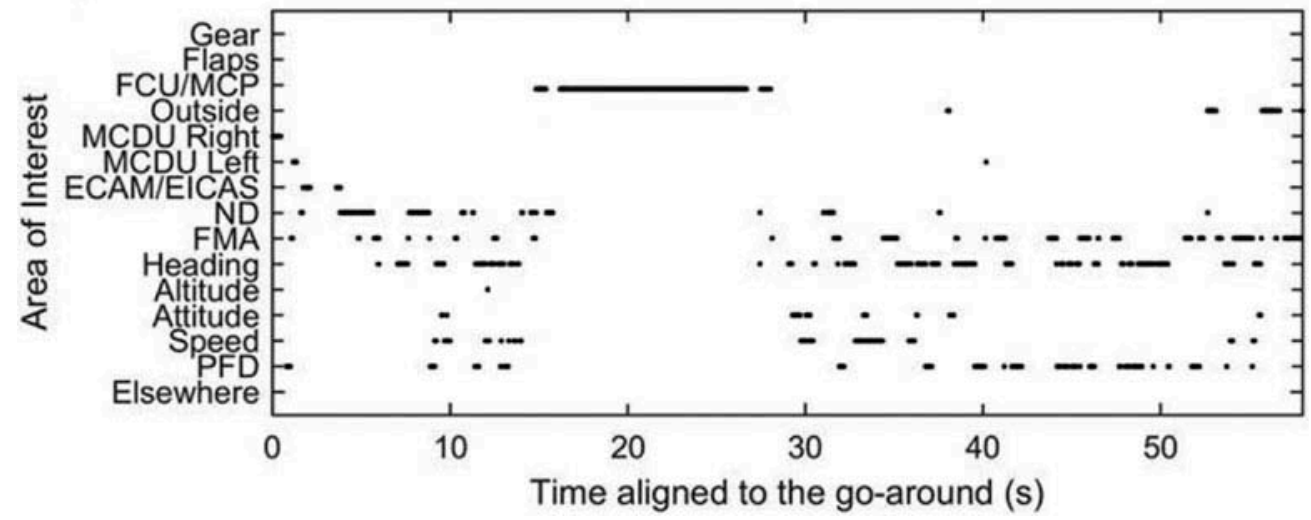

Figure 5. Ocular behavior of Pilot Monitoring No.11 during the go-around phase. Note that this pilot was excessively focused on the flight control unit (FCU) $15 \mathrm{~s}$ after the beginning of the go-around. $\mathrm{MCP}=$ mode control panel; $\mathrm{MCDU}=$ Multipurpose Control Display Unit; ECAM/EICAS = Electronic Centralized Aircraft Monitoring/Engine-Indicating and Crew-Alerting System; ND = navigation display; $\mathrm{FMA}=$ Flight Mode Annunciator; PFD = primary flight display.

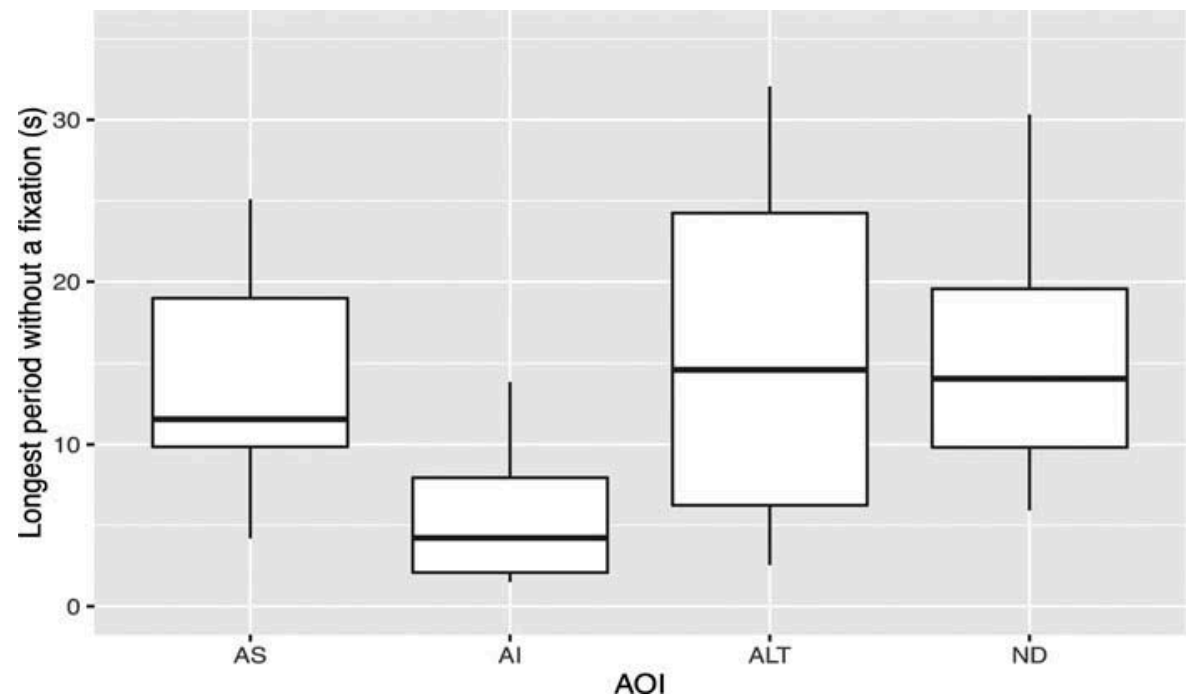

Figure 6. Maximum time between fixations on the four areas of interest (AOls) related to the energy or the trajectory of the aircraft during the go-around. These are shown as boxplots with whiskers. The bold band represents the median values of maximum time interval without a fixation of either pilot flying or pilot monitoring according to the six main AOls. The upper and lower ends of the boxes equals the $95 \%$ confidence interval. Whiskers represent ranges. AS = airspeed; Al = attitude indicator; ALT = altitude indicator; ND = navigation display. 


\section{How Did the Crew Manage the Go-Around Execution?}

The analysis of pilot performance revealed that all flight crews managed to stabilize the aircraft in accordance with ATC clearances. However, debriefing results indicated that the execution of the maneuver was particularly demanding. During the debriefing session, all PMs-except one-highlighted the complexity of the procedure and reported difficulties. In particular, they felt overwhelmed by the PF's callouts, ATC particular instructions, and the numerous actions to be performed during a short period of time. As stated by one pilot, "The diverse nature of the tasks and the speed at which they must be performed generate stress, notably when the startle effect is also included in the situation. Since stress reduces our ability to cope with complex actions, performance levels drop during go-arounds."

Moreover, only 3 crews out of 12 were able to correctly read back the complete ATC instructions while programming them rapidly in the flight-control panel. Recalling ATC instructions involves working memory abilities (Helleberg \& Wickens, 2003; Risser, Scerbo, Baldwin, \& McNamara, 2003; Taylor, O'Hara, Mumenthaler, Rosen, \& Yesavage, 2005; Taylor et al., 1994) that are known to be negatively affected by pilot workload (Durantin, Scannella, Gateau, Delorme, \& Dehais, 2015; Gateau, Durantin, Lancelot, Scannella, \& Dehais, 2015). Two thirds of the crews committed at least one error and half of the crews experienced significant flight-path deviations. Importantly, such deviations appear to lead to numerous accidents observed during go-around (BEA, 2013). Particularly, the PM plays a crucial role for the monitoring of flight-path deviations (Reynal et al., 2016). In the next sections, we discuss the eye-tracking results that could support this hypothesis.

\section{How did the PF and the PM Distribute Their Visual Attention During the Management of the Go-Around?}

During the final approach, the PF's scanning behavior was consistent with that observed by Sarter et al. (2007; see Steelman et al., 2011 for detailed analysis) and Huettig, Anders, and Tautz (1999). Importantly, we found changes in the pilots' scanning patterns during the go-around execution:

- Both pilots paid less attention to the OTW during go-around, looking outside less than 5\% of the time. In contrast, they spent up to $40 \%$ looking outside during the final approach. This behavior is understandable because landing on the runway is no longer the objective. Pilots needed to redistribute their attention on the flight deck to control the go-around manoeuver. This finding is in line with previous studies that demonstrated that the OTW is mainly scanned during approach (Huettig et al., 1999; Sarter et al., 2007).

- Airspeed scanning increased for both pilots. This is understandable due to the increased concern for stall at a potential high angle of attack and the need to retract the flaps with regard to specific speed values.

- ND monitoring increased for both pilots. This behavior is consistent with the careful monitoring of the trajectory and potential incoming traffic.

In addition, there were important shifts in relative responsibility for the two pilots:

- The PF devoted more visual attention to AI monitoring than did the PM. This is logical because this instrument displays the flight director. Indeed, the PF had to follow the flight director to fly the selected path during go-around.

- The PM, shedding some visual attention for the two instruments above (AI and ND), greatly increased FCU scanning, involved with setting changing flight modes and targets. 
In addition, the analysis of the explore/exploit ratio confirmed that the PF and PM used different ocular behaviors during the go-around. The PF was mainly in an exploit/focus mode, whereas the $\mathrm{PM}$ was in a more explore/monitoring mode. This finding is also consistent with the crew's attentional distribution during go-around. The PF looked mainly at three AOIs located in the primary flight display (PFD; speed, attitude and altitude indicators: 70\%). This result confirms that the role of the PF is to "fly" the aircraft while controlling the flight path. In contrast, the PM's visual attention during the go-around is spread more broadly over the different AOIs, with briefer dwells mainly to check that parameters are within range. Taken together, these results confirmed that the PF and the PM used different scanning strategies according to their predefined roles.

\section{Did the PF's and the PM's Visual Scan Ensure an Efficient Cross-Checking of the Flight Parameters?}

The pilot-performance results emphasized that teamwork was not efficient for more than half of the crew during go-around execution because it led to error detection issues. How can we explain these deviations? Was this due to collective or individual "neglect" of specific AOIs? Is it possible to make a link between visual scanning behavior and overall crew performance? We might expect some differences here, based on the prior research of Wickens et al. (2008) that proficiency in traffic detection was related to individual differences in overall scanning, and of Bellenkes, Wickens, and Kramer (1997) and Schriver, Morrow, Wickens, and Talleur (2008), who observed instrumentscanning differences related to pilot expertise. Lefrancois, Matton, Gourinat, Peysakhovich, and Causse (2016) showed that gaze allocation of pilots who failed to stabilize their approach was suboptimal and more variable compared to the more proficient pilots.

Our statistical analyses disclosed that only one AOI clearly discriminated the six best from the six poorest performing crews: the AI. The poorer performing crews, particularly the PM, allocated significantly less attention to the AOI. Although none of the crews experienced aerodynamic stall during our experiment, the monitoring of the aircraft's energy state is critical and has been a contributing factor in several loss-of-control accidents during the go-around (BEA, 2013). This assumption is consistent with a recent eye-tracking study that revealed that PMs exhibited insufficient monitoring of speed during final approach (Reynal et al., 2016). Moreover, the analysis of the maximum time interval without a fixation on the relevant AOIs by the crew (see Figure 6) also appears to support this lack of monitoring. These qualitative results revealed that there were important lapses of time during which critical parameters such as the airspeed indication (12 s) or the altimeter (14 s) were not glanced at by any crew member. Keeping in mind that the mean time of the go-around execution was about $75 \mathrm{~s}$, we could argue that any deviations of these parameters might remain unnoticed.

Eventually some explanations might be found in the PF's and the PM's visual strategies on specific AOIs. The individual eye-tracking analyses revealed that half of the PFs did not glance at the landing-gear indicator to verify that their PM effectively retracted it. In one case, the crew performed the go-around with the landing gear still lowered. More interestingly, four PFs out of six who deviated from the expected trajectory did not verify their PM's inputs. These PFs were following the flight director displayed on the AI. Two of these PFs (2 and 8) were particularly focused on the flight director to follow the flight path during the go-around. For instance, the PF 2 was so focused during $11 \mathrm{~s}$ on flying the flight director that he remained unaware that his PM had programmed an erroneous lateral flight path. Another noticeable illustration of such attentional issues occurred with PF 8 , who focused for $22 \mathrm{~s}$ on the vertical flight path to capture the target altitude, to the detriment of the monitoring of the horizontal flight. This attentional fixation on one axis to the detriment of another has been identified as a causal factor of critical events during the approach phase (BEA, 2004a, 2004b). 
For their part, the PMs failed to detect their PFs' flight-path deviation in five cases out of six. PM 9 and 11 were highly focused on the flight-control panel for more than 12 and $15 \mathrm{~s}$, respectively (see Figure 5) when their PF deviated. It is worth noting that all PMs spent a substantial amount of time (13.3\%) interacting with the flight-control panel, entering the ATC instructions. In general, pilots are trained to glance at the PFD while entering the data in the flight-control panel but none of the PMs exhibited this expected behavior. Another task that captured the three other PMs' attention $(2,7$ and 8$)$ was the flaps management, which prevented them from monitoring the flight path. These suboptimal monitoring abilities exhibited by some PMs are consistent with a recent eye-tracking study that revealed that PMs exhibited inadequate scanning during final approach (Reynal et al., 2016).

\section{Conclusions}

Our results confirmed that the go-around was a challenging task and that eye tracking provides valuable data to better understand pilots' performance. More interestingly, the qualitative and quantitative analyses of this study expanded the earlier findings from the ASAGA survey and accident analysis during go-around (BEA, 2013). Especially the eye-tracking measurements have highlighted several issues related to cockpit design and the monitoring of the flight parameters.

First, two user interfaces, namely the flight director (displayed in the AI) and the FCU have sometimes excessively captured respectively the PF's (see Table 1) and PM's visual attention (see Table 1 and Figure 3). Emphasis should be placed on training the PF to avoid excessive visual tunneling on the flight director, whereas the PM should be trained to interact with the FCU when flying low level; that is, checking the settings on the PFD while entering the data on the FCU.

Second, the eye-tracking measurements emphasized the essential role of the PM in the detection of flight-parameter deviations. The PM's numerous tasks (e.g., interaction with ATC, FCU settings, and flaps management) can leave this pilot ill equipped to face the sudden onsets of these actions and to monitor the flight path in the meantime. These results might appear surprising, as primary flight training emphasizes instrument scanning and cross-checking. Further studies are needed to confirm these findings as our sample size was small. It would also be relevant to manipulate other variables, such as round dial versus glass cockpit, low versus high level of automation, or experienced versus newly trained pilots, to disentangle all the variables that might affect visual scanning.

We believe that our results with those of others (Lefrancois et al., 2016; Reynal et al., 2016) support the recommendation made by the Federal Aviation Administration, stating that by March 2019, air carriers must include specific training to improve monitoring (see Flight Safety Foundation, 2014, p. 3). Specifically, our findings propose that training should emphasize the cross-monitoring of the primary flight parameters related to the energy state and the flight path of the airplane in demanding flight scenarios.

\section{ORCID}

Frédéric Dehais (D) http://orcid.org/0000-0003-0854-7919

\section{References}

BEA. (2000). Accident 23 August 2000 on approach to Bahrain A320 (BEA a40-ek000823). Paris, France: Author. BEA. (2004a). Accident on 22 June 2003 at Guipavas (21) to the Bombardier Canadair CL-600 2B 19 registered F-GRJS operated by Brit Air (No. f-js030622a). Paris, France: Author.

BEA. (2004b). Serious incident at Nantes on 21 March 2004 to the MD-83 registered SU-BMF operated by Luxor Air (No. su-f040321a). Paris, France: Author.

BEA. (2013). Study of aeroplane state awareness during go-around (No. FRAN-2013-023). Paris, France: Author.

Bellenkes, A. H., Wickens, C. D., \& Kramer, A. F. (1997). Visual scanning and pilot expertise: The role of attentional flexibility and mental model development. Aviation, Space, and Environmental Medicine, 68(7), 569-579. 
Cohen, J. (1992). Statistical power analysis. Current Directions in Psychological Science, 1(3), 98-101. doi:10.1111/14678721.ep10768783

Dehais, F., Causse, M., \& Pastor, J. (2008, June). Embedded eye tracker in a real aircraft: New perspectives on pilot/ aircraft interaction monitoring. Paper presented at ICRAT'08 Conference, Fairfax, VA.

Dehais, F., Peysakhovich, V., Scannella, S., Fongue, J., \& Gateau, T. (2015). Automation surprise in aviation: Real-time solutions. In P. Palanque, J. Vanderonckt, and M. Winckler (Eds.), Proceedings of the 33rd annual ACM conference on Human Factors in Computing Systems (pp. 2525-2534). New York: ACM Press.

Dehais, F., Tessier, C., Christophe, L., \& Reuzeau, F. (2010). The perseveration syndrome in the pilot's activity: Guidelines and cognitive countermeasures. In Proceedings of Human Error, Safety and Systems Development (pp. 68-80). New York: Springer.

Durantin, G., Scannella, S., Gateau, T., Delorme, A., \& Dehais, F. (2015). Processing functional near infrared spectroscopy signal with a Kalman filter to assess working memory during simulated flight. Frontiers in Human Neuroscience, 9.

Dutch Safety Board. (2010). Crashed during approach, Boeing 737-800, near Amsterdam Schiphol Airport, 25 February 2009. The Hague, The Netherlands: Author.

Flight Safety Foundation. (2014). The active pilot monitoring working group: A practical guide for improving flight path monitoring. Virginia: Author.

Gateau, T., Durantin, G., Lancelot, F., Scannella, S., \& Dehais, F. (2015). Real-time state estimation in a flight simulator using fNIRS. PLoS ONE, 10(3), e0121279. doi:10.1371/journal.pone.0121279

Goldberg, J. H., \& Kotval, X. P. (1999). Computer interface evaluation using eye movements: Methods and constructs. International Journal of Industrial Ergonomics, 24, 631-645. doi:10.1016/S0169-8141(98)00068-7

Helleberg, J., \& Wickens, C. D. (2003). Effects of data link modality and display redundancy on pilot performance: An attentional perspective. International Journal of Aviation Psychology, 13, 189-210. doi:10.1207/ S15327108IJAP1303_01

Huettig, G., Anders, G., \& Tautz, A. (1999, March). Mode awareness in amodern glass cockpit: Attention allocation to mode information. Paper presented at the 10th International Symposium on Aviation Psychology, Columbus, $\mathrm{OH}$.

Kasarskis, P., Stehwien, J., Hickox, J., Aretz, A., \& Wickens, C. (2001). Comparison of expert and novice scan behaviors during VFR flight. In Proceedings of the 11th International Symposium on Aviation Psychology. Columbus, $\mathrm{OH}$ : Ohio State University.

Lefrancois, O., Matton, N., Gourinat, Y., Peysakhovich, V., \& Causse, M. (2016, September). The role of pilots' monitoring strategies in flight performance. Paper presented at the European Association for Aviation Psychology Conference, Cascais, Portugal.

Moray, N. (1986). Monitoring behavior and supervisory control. In K. Boff, L. Kaufman, \& J. Thomas (Eds.), Handbook of perception and human performance (Vol. 2, pp. 40-51). New York, NY: Wiley.

Mumaw, R. J., Sarter, N. B., \& Wickens, C. D. (2001, May). Analysis of pilots' monitoring and performance on an automated flight deck. Paper presented at the 11th biennial meeting of the International Symposium on Aviation Psychology, Columbus, OH.

National Transportation Safety Board. (2013). Crash during a nighttime nonprecision instrument approach to landing UPS Flight 1354 airbus A300-600, N155UP Birmingham, Alabama August 14, 2013 (NTSB/AAR-14/02 PB2014107898). Washington: Author.

National Transportation Safety Board. (2015). Descent below visual glidepath and impact with seawall, Asiana Airlines flight 214 Boeing 777-200ER, HL7742, San Fransisco, California, July 6, 2013 (NTSB/AAR-14/01 PB2014-105984). Washington: Author.

Pinet, J., \& Sheridan, T. B. (2016). Book review: Facing the unexpected in flight. IEEE Aerospace and Electronic Systems Magazine, 31(8), 46.

Pizziol, S., Tessier, C., \& Dehais, F. (2014). Petri net-based modelling of human-automation conflicts in aviation. Ergonomics, 57, 319-331. doi:10.1080/00140139.2013.877597

Regis, N., Dehais, F., Tessier, C., \& Gagnon, J. (2012). Ocular metrics for detecting attentional tunnelling. Toulouse, France: Human Factors and Ergonomics Society-Chapter Europe.

Reynal, M., Colineaux, Y., Vernay, A., \& Dehais, F. (2016, October). Pilot flying vs. Pilot monitoring during the approach phase: An eye-tracking study. Paper presented at HCI-Aero 2016, International Conference on HumanComputer Interaction in Aerospace, Paris.

Reynal, M., Rister, F., Scannella, S., Wickens, C. D., \& Dehais, F. (2017, May). Investigating pilot's decision making when facing an unstabilized approach: An eye tracking study. Paper presented at the 19th Biennial International Symposium on Aviation Psychology, Dayton, OH.

Risser, M. R., Scerbo, M. W., Baldwin, C. L., \& McNamara, D. S. (2003). ATC commands executed in speech and text formats: Effects of task interference. In Proceedings of the 12th Biennial International Symposium on Aviation Psychology (pp. 999-1004), Dayton, OH.

Sarter, N., Mumaw, R., \& Wickens, C. (2007). Pilots' monitoring strategies and performance on automated flight decks: An empirical study combining behavioral and eye-tracking data. Human Factors, 49, 347. doi:10.1518/ 001872007X196685 
Schriver, A. T., Morrow, D. G., Wickens, C. D., \& Talleur, D. A. (2008). Expertise differences in attentional strategies related to pilot decision making. Human Factors: The Journal of the Human Factors and Ergonomics Society, 50, 864-878. doi:10.1518/001872008X374974

Spangler, C., \& Park, A. (2010). Loss of control on Approach Colgan Air, Inc., operating as Continental Connection Flight 3407 Bombardier DHC-8-400, N200WQ Clarence Center, New York February 12, 2009. In ACM SIGGRAPH 2010 Dailies (p. 7). New York: ACM.

Starcke, K., \& Brand, M. (2012). Decision making under stress: A selective review. Neuroscience \& Biobehavioral Reviews, 36, 1228-1248. doi:10.1016/j.neubiorev.2012.02.003

Steelman, K. S., McCarley, J. S., \& Wickens, C. D. (2011). Modeling the control of attention in visual workspaces. Human Factors: The Journal of the Human Factors and Ergonomics Society, 53, 142-153. doi:10.1177/ 0018720811404026

Stokes, A. F., Kemper, K. L., \& Marsh, R. (1992). Time-stressed decision-making: A study of expert and novice aviators (Tech. Rep. No. ARL-93-1/INEL-93-1). Savoy, IL: University of Illinois, Aviation Research Laboratory.

Stokes, A., \& Kite, K. (1994). Flight stress: Stress, fatigue, and performance in aviation. Burlington, VT: Ashgate.

Taylor, J., O’Hara, R., Mumenthaler, M., Rosen, A., \& Yesavage, J. (2005). Cognitive ability, expertise, and age differences in following air-traffic control instructions. Psychology and Aging, 20, 117-133. doi:10.1037/08827974.20.1.117

Taylor, J., Yesavage, J., Morrow, D., Dolhert, N., Brooks, J., III, \& Poon, L. (1994). The effects of information load and speech rate on younger and older aircraft pilots' ability to execute simulated air-traffic controller instructions. The Journal of Gerontology, 49, P191. doi:10.1093/geronj/49.5.P191

Tessier, C., \& Dehais, F. (2012). Authority management and conflict solving in human-machine systems. AerospaceLab, 4, 1-10.

UK Civilian Aviation Authority. (2013). Loss of control action group, monitoring matters-Guidance on the development of pilot monitoring skills (CAA Paper 2013/02). London: Author.

U.S. Department of Transportation. (2015). Safety alert for operators, roles and responsibility for PF and PM (No. 15011). Washington, DC: Flight Standards Service.

Wickens, C. D., Hooey, B. L., Gore, B. F., Sebok, A., \& Koenicke, C. S. (2009). Identifying black swans in NextGen: Predicting human performance in off-nominal conditions. Human Factors, 51, 638-651. doi:10.1177/ 0018720809349709

Wickens, C. D., McCarley, J. S., Alexander, A. L., Thomas, L. C., Ambinder, M., \& Zheng, S. (2008). Attentionsituation awareness (A-SA) model of pilot error. In D. Foyle and B. Hooey (Eds.), Human performance modeling in aviation (pp. 213-239). Mahwah, NJ: Erlbaum 